\title{
Basic Physical - Mechanical Properties of Geopolymers Depending on the Content of Ground Fly Ash and Fines of Sludge
}

\author{
Alena Sičáková, Nadežda Števulová \\ Technical University of Košice, Slovakia \\ Civil Engineering Faculty, Institute of Environmental Engineering \\ e-mail: alena.sicakova@tuke.sk,nadezda.stevulova@tuke.sk
}

\begin{abstract}
The binding potential of fly ash (FA) as a typical basic component of building mixtures can be improved in mechanical way, which unfolds new possibilities of its utilization. This paper presents the possibilities of preparing the geopolymer mixtures based on ground $\left(\mathrm{d}_{\mathrm{m}}=31.0 \mu \mathrm{m}\right) \mathrm{FA}$, used in varying percentages to the original (unground; $\mathrm{d}_{\mathrm{m}}=74.1 \mu \mathrm{m}$ ) one. As a modification, fine-grain sludge from the process of washing the crushed aggregates was used as filler in order to obtain mortar-type material. The basic physical-mechanical properties of mixtures are presented and discussed in the paper, focusing on time dependence. The following standard tests were executed after 2, 7, 28, and 120 days: density, total water absorption, flexural strength, and compressive strength. Ground FA provided for positive effect in all tested parameters, while incorporation of fine portion of sludge into the geopolymer mixture does not offer a significant technical profit. On the other hand, it does not cause the decline in the properties, so the environmental effect (reduction of environmental burden) can be applied through its incorporation into the geopolymer mixtures.
\end{abstract}

Key words: geopolymer; fly ash; washing aggregate sludge; grinding; strength; water absorption.

\section{Introduction}

Many attempts have been made to minimize the use of cement as a binder in concrete production. The use of geopolymer as a binder in concrete production not only results in reduced $\mathrm{CO}_{2}$ emission because of the elimination of cement, but also valorizes the aluminosilicate industrial by-products to produce environment-friendly construction material [1].

Geopolymers are members of the inorganic polymers family. The chemical composition of the geopolymer material is similar to natural zeolitic material, but the microstructure is amorphous. The polymerization process involves a substantially fast chemical reaction of SiAl minerals under alkaline condition, resulting in a three-dimensional polymeric chain and ring structure consisting of Si-O-Al-O bonds [2]. This alumina-silicate binding material is synthetized by alkali activation of solid alumina-silicate raw materials such as fly ash (FA), 
ground granulated blast furnace slag, metakaoline, rice husk ash, etc. The alkali metal hydroxide and silicate solution are the standard activators [3-6].

The utilization of FA in the development of geopolymeric materials for construction purposes has been and continues to be the subject of many research studies [7-11]. The works done on geopolymer technology show a significant potential for its utilization in construction, particularly low-calcium FA [12-13]. The possibility of using low-calcium FA to produce geopolymers also has environmental benefits. Quite a large amount of FA is utilized for cement concrete production, but the high-calcium type of FA is required in this case. The calcium content of the FA is perhaps the best indicator of how the FA will behave in concrete, although other compounds such as alkalis $\left(\mathrm{Na}_{2} \mathrm{O}\right.$ and $\left.\mathrm{K}_{2} \mathrm{O}\right)$, carbon (usually measured as LOI), and sulphate $\left(\mathrm{SO}_{3}\right)$ may also affect the performance of the FA. High-calcium FA (> $20 \% \mathrm{CaO}$ ) may be produced from lignite or sub-bituminous coals and are comprised of calcium-alumino-silicate glass and a wide variety of crystalline phases in addition to those found in low-calcium FA. Some of these crystalline phases react with water. This, coupled with the more reactive nature of the calcium-bearing glass, makes such types of FA react more rapidly than low-calcium types and renders the FA both pozzolanic and hydraulic in nature. These FA types will react and harden when mixed with water due to the formation of cementitious hydration products. If the calcium content of the FA is high enough, it is possible to make concrete of moderate strength using the FA as the sole cementing material.

On the other hand, low-calcium FA $(<8 \% \mathrm{CaO})$ is invariably produced from anthracite or bituminous coals and is predominantly composed of alumino-silicate glasses with varying amounts of crystalline quartz, mullite, hematite and magnetite. These crystalline phases are essentially inert in cement concrete and the glass requires a source of alkali or lime (for example $\left.\mathrm{Ca}(\mathrm{OH})_{2}\right)$ to react and form cementitious hydrates. Such FA types are pozzolanic and display no significant hydraulic behaviour [14-15]. Therefore, it is very significant that some possibility of utilizing the low-calcium FA exists. Low-calcium FA has been successfully used to manufacture geopolymer concrete, wherein the silicon and aluminium oxides constituted about $80 \%$ of the mass, with a Si-to-Al ratio of about 2.0. The content of the iron oxide usually ranged from $10-20 \%$ by mass, while the calcium oxide content was less than $5 \%$ by mass $[16]$.

The effect of the fineness of FA on geopolymer's properties is also widely discussed. Changes induced in materials during the mechanical treatment process include reduction in particle size, changes in particle morphology, increase in specific surface area, structural defects formation, decrease in crystallinity, and implied structural rearrangement. The most important consequence of transformation in material during the mechanical activation is its enhanced reactivity. Improved reactivity is primarily the result of increased particle fineness and formation of amorphous regions in structure. Mechanical activation, as a method that can improve FA reactivity, is often applied in different applications of this material. It is known that particles with diameter below $45 \mu \mathrm{m}$, obtained through various methods of mechanical treatment, tend to improve mechanical strength of mortar when used as a supplementary cementitious material [7]. According to Jamkar et al. [16], the compressive strength results show that the FA fineness plays a vital role in the activation of geopolymer concrete. An increase in the fineness improved both workability and compressive strength. It was also observed that finer particles increased the rate of reaction, and led to requirement of less heating time to achieve a given strength. Moreover, Gunasekara et al. [13] describe the 
highest compressive strength of geopolymer mortar resulting from the highest fineness ratio of FA used.

Washing aggregate sludge is a waste produced during the classification of sand and gravel in gravel pit, or while washing crushed aggregates in quarry (quarry washings). Its use in production of building materials (concrete or mortar) is rare. According to Cresswell [17], crushed rock fines are the material that cannot find a use in the local market, but has the potential to be used for a number of applications other than as fine aggregate. They may have compositions suitable for incorporation into brick manufacture or cement production. Together with González-Corrochano et al. [18], they prove that finer portions may also be suitable for the production of manufactured (light-weight) aggregates.

This paper is aimed on proving the application of mechanically treated (ground) FA for production of FA-based geopolymer. As a modification, fine-grain sludge - a by-product of washing the crushed aggregates-was used as filler for obtaining a mortar-type material. Finally, standard cement mixture was prepared using the same fillers for comparison. The experiment was also intended as environmental support in terms of utilization of specific/regional kinds of waste-low-calcium type of FA, ground granulated blast furnace slag, and washing aggregate sludge.

\section{Materials and methods}

The experiment is focused on the testing of standard FA-based geopolymer prepared by the acceptation of referenced recommendations for composition, while using regional materials. In addition to the recommended ratio of components of the geopolymer mixture, the influence of the treatment of two basic components was additionally tested: grinding of FA and separation of fine sludge. In this paper, basic physical-mechanical properties of mixtures are presented and discussed with emphasis on time development, while cement-based mixture was tested for comparison.

The materials for tested mixtures were as follows:

- Original fly ash: PVT-FA (coming from Heating plant, class F) and Ground fly ash: GPVT-FA - as basic component of geopolymer,

- Ground granulated blast furnace slag: GGBFS (Steel making factory, Slovakia) - as intensificator,

- $\mathrm{Na}_{2} \mathrm{SiO}_{3}+\mathrm{NaOH}$ - as activator,

- Sludge - the material from processing (washing) the crushed aggregates, coming from an Eastern Slovakia producer of crushed aggregates - as microfiller

- Ordinary Portland Cement - OPC (CEM I 42.5 R, Slovakia) - as binder

The chemical composition of PVT-FA, GPVT-FA, GGBFS, cement and sludge are given in Tab. 1. The parameter of grain size distribution is also given by distribution values on the $\mathrm{X}-$ axis $\mathrm{d}(0.1), \mathrm{d}(0.5)$ - median and $\mathrm{d}(0.9)$, and by the mean value $\mathrm{dm}$.

As for fly ash, the influence of fine-grain form was tested. For this purpose, results of the previous experiment which was focused on the finding the grinding conditions for reducing its particle size were taken into account [19]. Accordingly, sample prepared by following grinding conditions was selected for this experiment: grinding time 60 minutes; grist:grinding 
media proportion: 2:1 (GPVT-FA). The mean size $d_{m}$ was reduced by grinding from 74.1 to $31.02 \mu \mathrm{m}$, which is practically the mean size of cement particles. Chemical composition of PVT falls in the values given in [16]; the calcium oxide content of PVT-FA is less than 10\% (2.58), the silicon and aluminium oxides constitute about $74 \%$ by mass, and Si-to-Al ratio is 2.1. Only the content of the iron oxide is a bit lower (6.4\% by mass).

The sludge was withdrawn from the dewatering pond and dried, after which a portion $<125$ $\mu \mathrm{m}$ was separated using standard sieve. The aim was to get a micro-filler. The value of $\mathrm{d}(0.9)=149.8 \mu \mathrm{m}$ comes from the accuracy limit of such a mechanical process. However, the material can be classified as having $\mathrm{d}_{\mathrm{m}}=83.55 \mu \mathrm{m}$.

Table 1: Chemical composition and grain size distribution parameters of input materials

\begin{tabular}{|l|l|l|l|l|l|l|l|l|l|}
\hline \multirow{2}{*}{ Materials } & \multicolumn{4}{|c}{ Oxide Composition } & \multicolumn{3}{c|}{ Parameters of grain size distribution } \\
\cline { 2 - 12 } & $\mathrm{SiO}_{2}$ & $\mathrm{CaO}$ & $\mathrm{MgO}$ & $\mathrm{Fe}_{2} \mathrm{O}_{3}$ & $\mathrm{Al}_{2} \mathrm{O}_{3}$ & $\mathrm{~d}(0.1)$ & $\mathrm{d}(0.5)$ & $\mathrm{d}(0.9)$ & $\mathrm{d}_{\mathrm{m}}$ \\
\hline PVT-FA & 51.11 & 2.58 & 1.18 & 6.40 & 23.21 & 3.97 & 20.44 & 84.73 & 74.10 \\
\hline GPVT-FA & 49.72 & 2.49 & 1.09 & 6.37 & 22.32 & 3.48 & 14.53 & 52.81 & 31.02 \\
\hline GGBFS & 41.28 & 35.98 & 12.85 & 0.39 & 6.30 & 3.61 & 19.03 & 111.5 & 49.46 \\
\hline OPC & 19.87 & 64.36 & 4.61 & 3.18 & 3.99 & 3.20 & 17.69 & 49.57 & 29.90 \\
\hline Sludge (separated) & 42.66 & 5.83 & 5.04 & 6.54 & 11.19 & 17.49 & 82.50 & 149.8 & 83.55 \\
\hline
\end{tabular}

Table 2 illustrates the principle of tested mixtures. For mixtures T1 - T3 (geopolymer pastes), FA is intended as basic geopolymer filler, while the unground and ground forms are used in three combinations. Mixtures T4 and T5 (mortars) contain ground FA only (GPVT-FA), while $30 \%$ is replaced by sludge microfiller. T4 is based on geopolymer reaction similar to the previous mixtures, while T5 contains cement binder only and is considered as a comparative sample.

Table 2: The composition of experimental geopolymer mixtures

\begin{tabular}{|l|c|c|c|c|c|c|}
\hline \multicolumn{2}{|c|}{$\begin{array}{c}\text { Composition of fillers } \\
{[\%]}\end{array}$} & \multicolumn{5}{|c|}{ Mixtures } \\
\cline { 3 - 7 } & T1 & T2 & T3 & T4 & T5 \\
\hline GPVT-FA & $\begin{array}{c}\text { 46\% of mixture } \\
\text { volume }\end{array}$ & 100 & 50 & - & 70 & 70 \\
\cline { 3 - 8 } & & - & 50 & 100 & - & - \\
\cline { 3 - 8 } PVT-FA & - & - & - & 30 & 30 \\
\hline Sludge $<125 \mu \mathrm{m}$
\end{tabular}

\begin{tabular}{|l|l|l|l|l|l|l|}
\hline \multicolumn{2}{|l|}{ Presence of other components } & & & & & \\
\hline $\mathrm{GGBFS}$ & $20 \%$ of fly ash & $\bullet$ & $\bullet$ & $\bullet$ & $\bullet$ & - \\
\hline $\mathrm{Na}_{2} \mathrm{SiO}_{3}$ & $16 \%$ of fly ash & $\bullet$ & $\bullet$ & $\bullet$ & $\bullet$ & - \\
\hline $8 \mathrm{M} \mathrm{NaOH}$ & $16.5 \%$ of fly ash & $\bullet$ & $\bullet$ & $\bullet$ & $\bullet$ & - \\
\hline $\mathrm{OPC}$ & - & - & - & - & $\bullet$ \\
\hline Water & $\bullet$ & $\bullet$ & $\bullet$ & $\bullet$ & $\bullet$ \\
\hline Plasticizer & $\bullet$ & $\bullet$ & $\bullet$ & $\bullet$ & $\bullet$ \\
\hline
\end{tabular}


Key parameters of geopolymer mixtures (ratio between the components) were selected as usual and their typical values were collected from a few publications [8, 9, 10, 20, 21], giving some standard starting level of experiment. The basic geopolymer mixture was designed according to these recommendations (see Table 3). Alkaline-activating agent for mixtures $\mathrm{T} 1$ - T4 was prepared by mixing the $\mathrm{Na}_{2} \mathrm{SiO}_{3}$ and $\mathrm{NaOH}$. The $\mathrm{SiO}_{2}$ to $\mathrm{Na}_{2} \mathrm{O}$ ratio (Ms Modulus) in the alkaline activating agent was adjusted by addition of $8 \mathrm{M} \mathrm{NaOH}$ to $\mathrm{Na}_{2} \mathrm{SiO}_{3}$ with a $\mathrm{Ms}=$ 2.5.

Table 3: Parameters of geopolymer mixtures

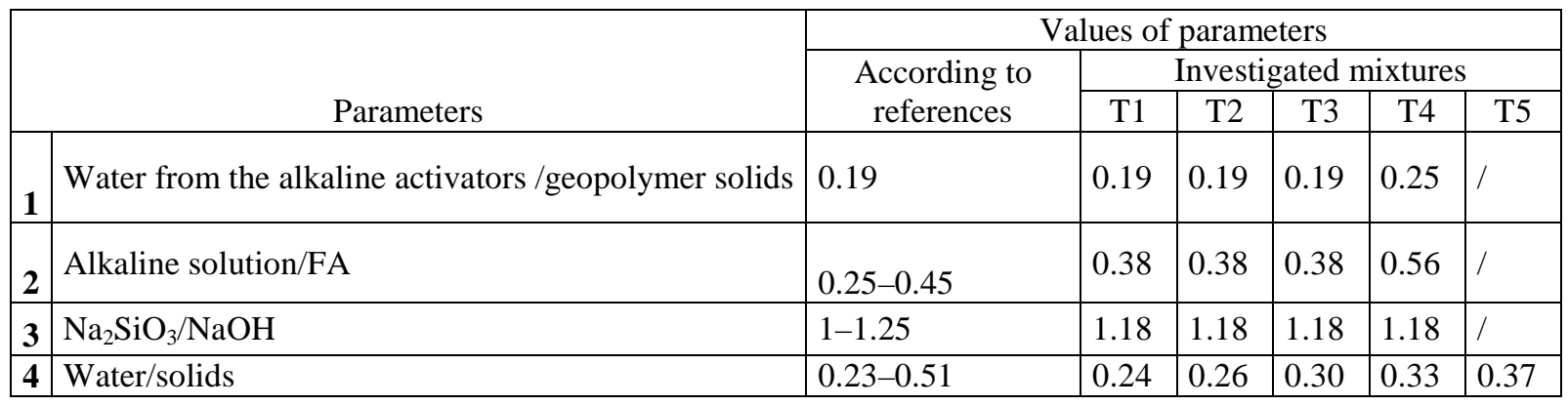

The samples (beams 40x40x160 mm) were cured at the laboratory temperatures covered by foil sheet at first, then under ambient humidity (50\%). Following standard tests (density, total water absorption, flexural strength and compressive strength) were executed after 2, 7, 28 and 120 days according to [22-24].

For providing information about molecular structure and the presence of specific functional groups in geopolymer samples based on various fly ash additions (T1-T3), infrared spectroscopy in transmission mode was used. FTIR measurements were carried out using Bruker Alpha Platinum-ATR spectrometer (BRUKER OPTICS, Ettingen, Germany). A total of 24 scans were performed on each sample in the range of $400-4000 \mathrm{~cm}^{-1}$.

\section{Results and discussion}

The results of tests on density, total water absorption, flexural strength, and compressive strength are reported in the following figures. For discussion of the mentioned properties, results are summarized in the graphs in two groups:

- $\quad$ T1, T2, and T3, where the influence of ground FA can be discussed

- T1, T4, and T5, where the effect of replacing a part of ground FA with the sludge, as well as effect of using cement binder instead the geopolymer reaction can be discussed

Values of individual properties in 120 days of setting and hardening range as follows: 1730 $2050 \mathrm{~kg} \cdot \mathrm{m}^{-3}$ (density), 12.6-18.9\% (water absorption), 2.6-3.6 MPa (flexural strength), and 9.1-17.2 MPa (compressive strength).

The results presented in Figures 1 to 4 indicate that all four presented parameters have a good relationship with each other, as it is a standard consequence of microstructure of matters: With decreasing density of sample, the strength decreases and total water absorptivity increases. The development of the properties in time is also clear: With the time, changes in the microstructure cause a reduction in the water absorption and increase in both the strength and density. 


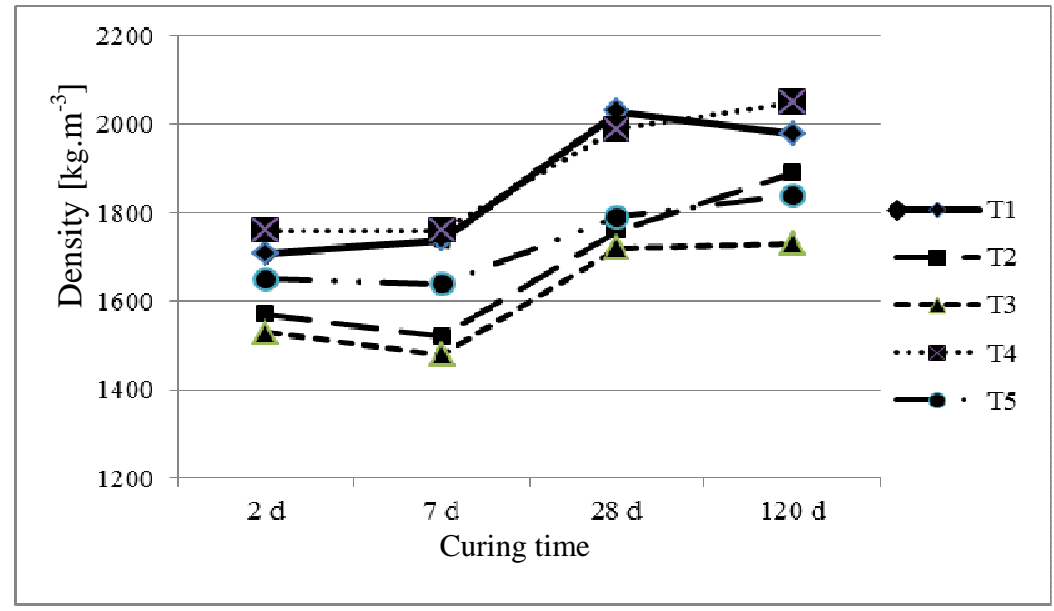

Figure 1: Density of samples T1-T5

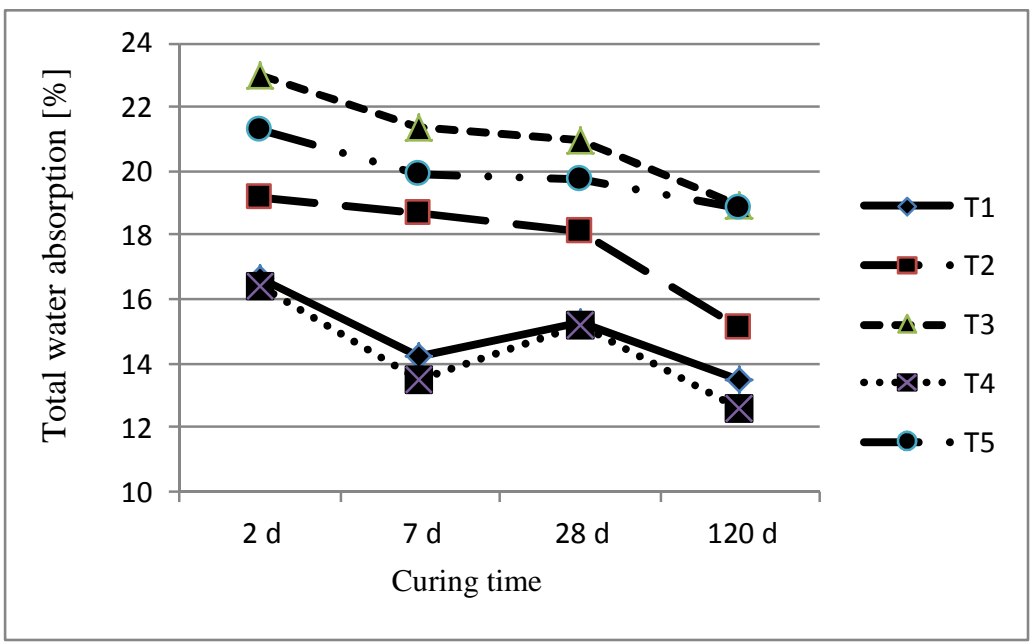

Figure 2: Total water absorption of samples T1-T5

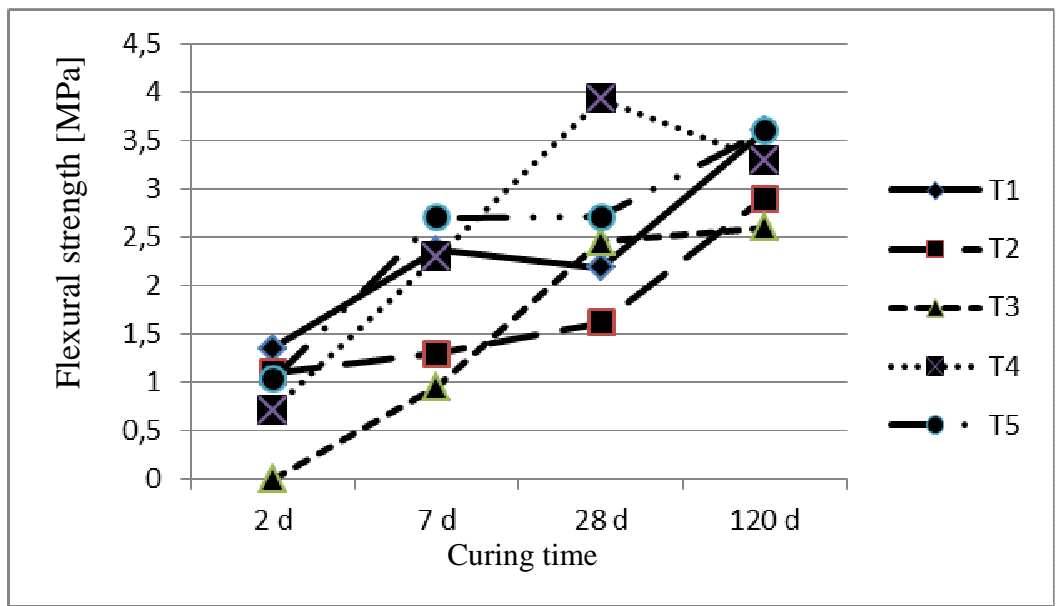

Figure 3: Flexural strength of samples T1-T5 


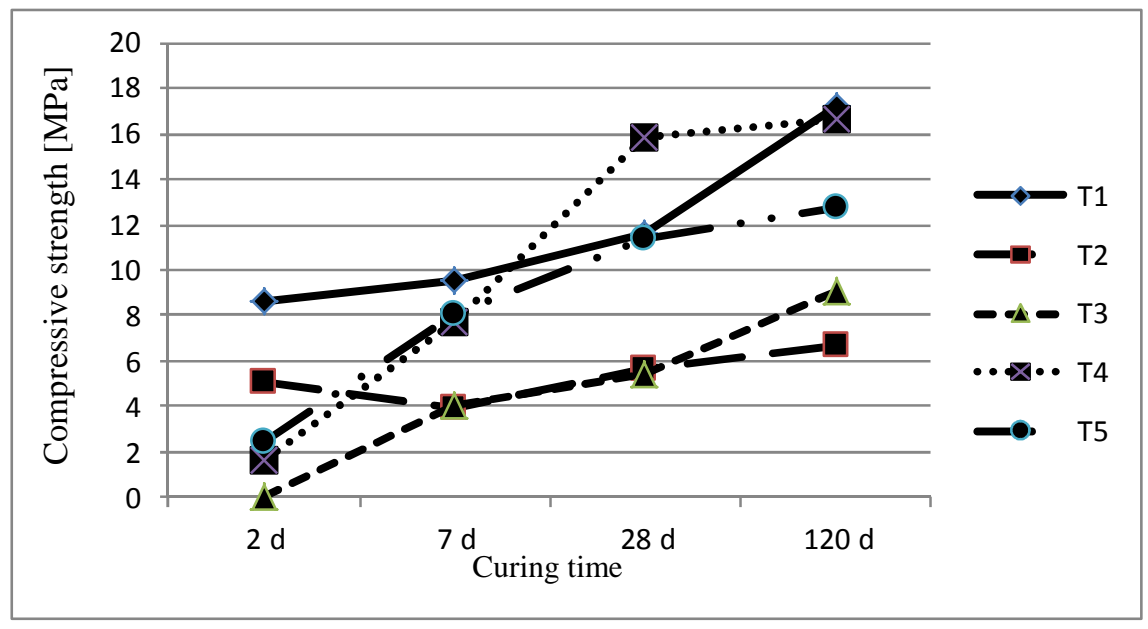

Figure 4: Compressive strength of samples T1-T5

Group T1, T2, and T3: The influence of FA granularity is confirmed in Figures $1-4$ comparing samples T1-T3. The best results (highest strength and lowest water absorption) are detected for sample T1 (100\% ground FA), while the worst results can be attributed in principle to T3 (100\% of unground FA). It is in agreement with the [25], where geopolymers produced with ground fly ash showed the increase in strength for finer fractions obtained by grinding. In fact, in terms of the density and strength, the results of samples with $100 \%$ unground FA (T3) and 50\% unground FA (T2) are very close. What is technically important is that the difference between $\mathrm{T} 1$ and other samples is significant with respect to compressive strength, including short-term two-day values. Values of presented properties of T1 in 28 days of setting and hardening are as follows: 2030 kg.m-3 (density), 15.3\% (total water absorption), 2.2 MPa (flexural strength), and 11.6 MPa (compressive strength).

Group T1, T4, and T5: The effect of replacing a part of ground FA with the sludge seems to be insignificant (see samples T1, T4 and T5 in Figures 1-5). There are a few differences between $\mathrm{T} 1$ and $\mathrm{T} 4$ in terms of flexural and compressive strength at certain points of time, but ultimately the results are settled. Results of density and total water absorption are very close. Differences between the geopolymer mixtures (T1 and T4) and cement based mixture (T5) are evident in the case of density and total water absorption: Positive changes were recorded for geopolymers, while results are in good relationship (lower is density, higher is water absorption). Tendencies in strengths are not quite clear. Results in flexural strength are close to $\mathrm{T} 1$ while results in compressive strength are close to T4, but only in the early ages. Taking into account total water absorption and later strengths, samples based on geopolymer reaction seem to be more favourable than samples based on cement.

The infrared spectroscopy analysis records are given in Figure 5 for original fly ash (PVTFA) and Figure 6 for geopolymer mixture T1 (100\% of ground fly ash: GPVT-FA). 


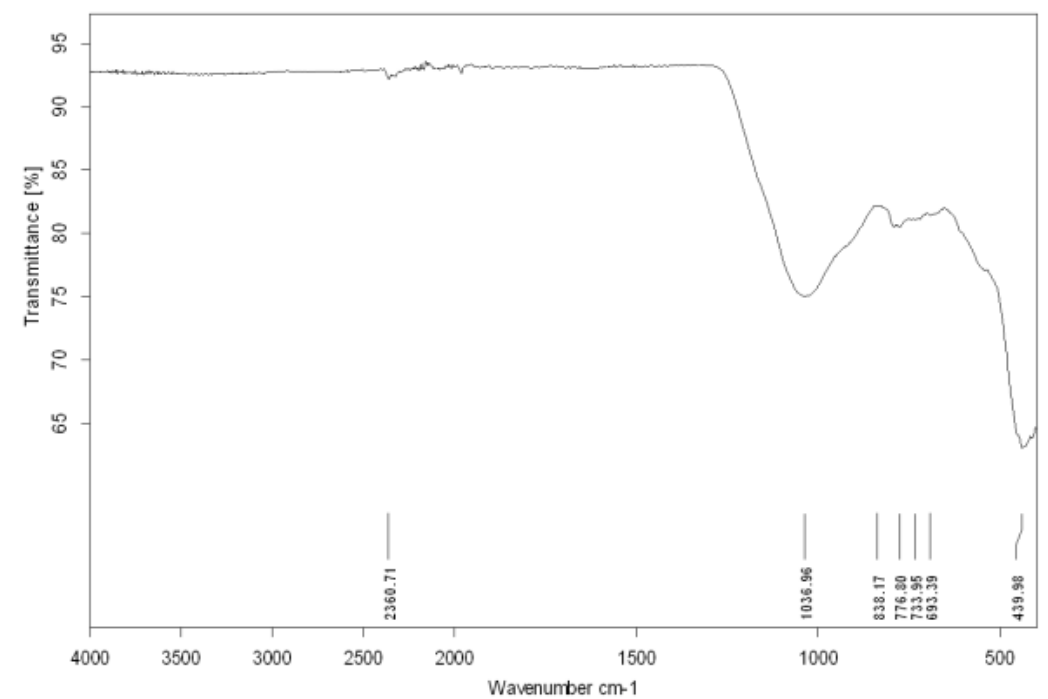

Figure 5: The infrared spectroscopy analysis of original fly ash PVT-FA

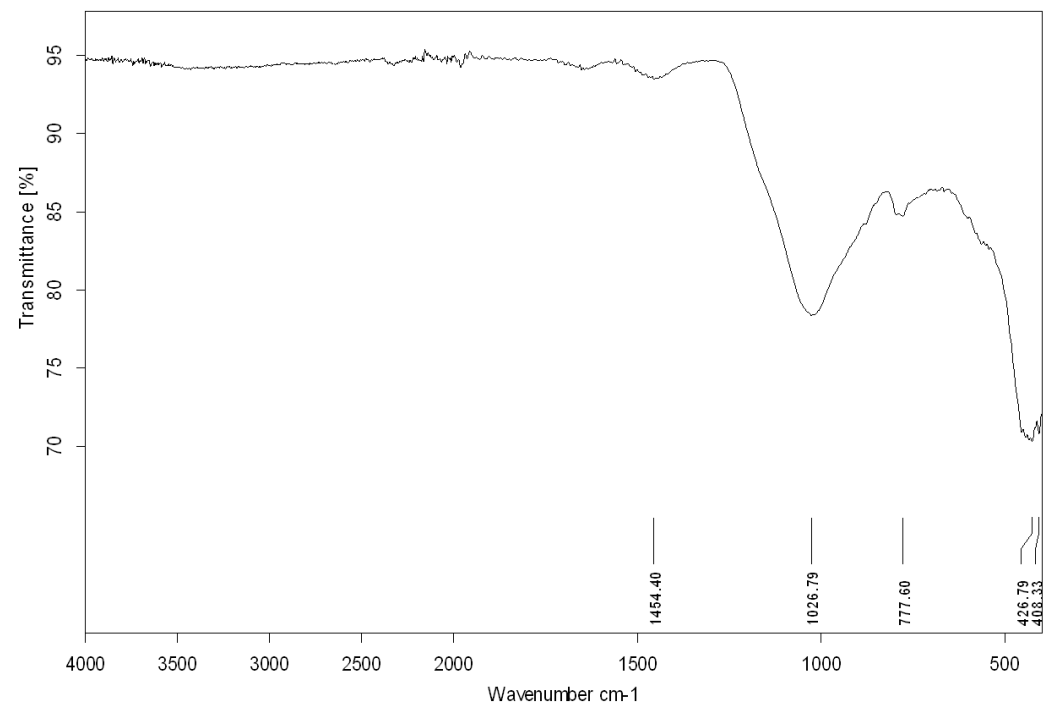

Figure 6: The infrared spectroscopy analysis of geopolymer mixture T1

As shown in Figures 5 and 6, the absorption peak positions observed by the FTIR spectra of the fly ash and the geopolymer sample T1 are almost identical. The major bands in the FTIR spectra of these substances and their assignments to vibrations of functional groups are summarized in Table 4. Measurements of another geopolymer concrete samples T2 (combination of ground and unground fly ash) and T3 (unground fly ash) showed the same IR bands in investigated region of wavenumber.

The broad absorption band at $1037 \mathrm{~cm}^{-1}$, peak of significant intensity at $440 \mathrm{~cm}^{-1}$, very weak peak at $2360 \mathrm{~cm}^{-1}$ and four peaks visible in the region of $839-690 \mathrm{~cm}^{-1}$ are recorded in the spectrum of fly ash (Fig. 5). In addition, spectrum of sample T1 (Fig. 6) contains two peaks at 1454 and $1652 \mathrm{~cm}^{-1}$, respectively. The band at $1454 \mathrm{~cm}^{-1}$ indicates stretching vibration of the $\mathrm{O}-\mathrm{C}-\mathrm{O}$ bond in calcite and could also contain a contribution of atmospheric carbonation of high alkaline $\mathrm{NaOH}$. The band at $1652 \mathrm{~cm}^{-1}$ comes from trace amount of water (bending 
vibration of $\mathrm{H}-\mathrm{O}-\mathrm{H})$. The strong peak at $1037 \mathrm{~cm}^{-1}$ is due to the $\mathrm{Si}-\mathrm{O}-\mathrm{Si}$ and $\mathrm{Al}-\mathrm{O}-\mathrm{Si}$ asymmetric stretching vibration [26]. In the case of geopolymer sample $\mathrm{T} 1$, it is shifted to lower frequency value $\left(1026 \mathrm{~cm}^{-1}\right)$. The more significant shift of this band to 976 and $969 \mathrm{~cm}^{-}$ ${ }^{1}$ was identified in fly-ash-based geopolymer lightweight concrete using foam agent [27]. Based on investigations in [28, 29, 30], this shift was explained by the formation of amorphous aluminosilicate gel phase due to dissolution of aluminium and silicon species from the fly ash surface in alkaline activator, followed by the polymerization of active surface groups and soluble species to form gel and, subsequently a hardened geopolymer structure. Principal band of Si-O stretching vibration in hydrated phase of C-S-H at $974 \mathrm{~cm}^{-1}$ and Si-O asymmetric stretching vibration of silicate, centered at $925 \mathrm{~cm}^{-1}$ attributed to $\left[\mathrm{SiO}_{4}\right]^{4-}$ vibration can be also included in the broad peak with maximum intensity at $1037 \mathrm{~cm}^{-1}[31,32]$. The bands at 877 and $777 \mathrm{~cm}^{-1}$ are assigned to O-C-O bond vibration in carbonate. Strong band in the region of $427-520 \mathrm{~cm}^{-1}$ seen in the spectra corresponds to the $\mathrm{Si}-\mathrm{O}$ bending modes $(452$ $\mathrm{cm}^{-1}$ - Si-O in-plane bending vibration; $522 \mathrm{~cm}^{-}{ }^{1}-\mathrm{Si}-\mathrm{O}$ out-of-plane bending vibration) in $\mathrm{SiO}_{4}$ tetrahedra of silicate.

The peak of very weak intensity at $2360 \mathrm{~cm}^{-1}$ represents the stretching and deformation vibration of $\mathrm{O}-\mathrm{H}$ and $\mathrm{H}-\mathrm{O}-\mathrm{H}$ groups from weakly-bound water molecules adsorbed on the surface or situated between the rings of the geopolymeric products [33].

Table 4: Identification of FTIR bands in PVT-FA and geopolymer sample T1

\begin{tabular}{|l|l|}
\hline Wavenumber $\left[\mathrm{cm}^{-1}\right]$ & Vibration of function group \\
\hline $3400-3100$ & $\mathrm{O}-\mathrm{H}$ and $\mathrm{H}-\mathrm{O}-\mathrm{H}$ \\
\hline 2360 & $\mathrm{O}-\mathrm{H}$ \\
\hline 1652 & $\mathrm{H}-\mathrm{O}-\mathrm{H}$ \\
\hline 1454 & $\mathrm{O}-\mathrm{C}-\mathrm{O}$ \\
\hline 1037,1026 & Si-O-Si and Al-O-Si \\
\hline 877 & $\mathrm{C}-\mathrm{O}$ \\
\hline 777 & $\mathrm{C}-\mathrm{O}$ \\
\hline $427-520$ & Si-O \\
\hline
\end{tabular}

\section{Conclusion}

This paper was focused on the utilization of regional alternative (waste) materials (FA and sludge) as components of standard geopolymer mixture. Their treatment (grinding in the case of FA and sorting in the case of sludge) represents a valuable input, leading to better influence on the technical parameters of final mixtures. The following conclusions can be formulated from the presented experiments:

- for proposed composition of experimental geopolymer mixtures based on ground fly ash, a formation of amorphous aluminosilicate gel phase, followed by the polymerization of active surface groups to form gel and, subsequently a hardened geopolymer structure was confirmed using FTIR analysis; 
- for FA based geopolymer, the results confirm the ground form of FA is being favourable for basic technical properties such as density, water absorption, flexural strength, and compressive strength;

- mixture using ground FA with $\mathrm{d}_{\mathrm{m}}=31.0 \mu \mathrm{m}$ instead of unground one with $\mathrm{d}_{\mathrm{m}}=74.0$ $\mu \mathrm{m}$ is significantly better in all parameters. Comparing 28 -day values, the density is higher by about $18 \%$, total water absorption is better by about $25 \%$, flexural strength is better by about $25 \%$, and compressive strength is better by about $10 \%$;

- incorporation of fine portion of sludge into the geopolymer mixture does not lead to a significant technical profit. However, the sludge can be utilized on the basis of the comparable properties. Here, an environmental point of view can be taken into account (amounts of FA and the sludge to be utilized);

- binders based on geopolymer reaction seem to be more favourable than samples based on cement, in terms of total water absorption and long-term strength.

\section{Acknowledgements}

This research has been carried out within the project ITMS "Center of excellent integrated research of progressive building constructions, materials and technologies" No. 26220120037 and within the project NFP 26220220051 "Development of progressive technologies for utilization of selected waste materials in road construction engineering", supported by the European Union Structural funds.

\section{References}

[1] I. Nikolič et al. (2012). Geopolymerization of fly ash as a possible solution for stabilization of used sandblasting grit. Zaštita Materiala. 53, 243-246. UDC: 504.3.056.

[2] J. Davidovits. (1994). High-Alkali Cements for 21st Century Concretes. Concrete Technology, Past, Present and Future. ACI SP 144, 383-397.

[3] L. Y. Huang, D. W. Li, Y. C. Shiau, S. Li \& K. X. Liu. (2015). Preparation and properties of geopolymer from blast furnace slag. Materials Research Innovations. 19(10), 413-419. DOI: 10.1179/1432891715Z.0000000002210.

[4] N. T. Ravindra, S. Ghosh. (2009). Effect of mix composition on compressive strength and microstructure of fly ash based geopolymer composites. ARPN Journal of Engineering and Applied Sciences. 4(4), 68-73.

[5] M. A. Villaquirán-Caicedo, R. Mejía-de Gutiérrez. Synthesis of ternary geopolymers based on metakaolin, boiler slag and rice husk ash. DYNA. 82 (194), 104-110. DOI: 10.15446/dyna.v82n194.46352.

[6] P. Rovnaník, K. Šafránková. (2016). Thermal Behaviour of Metakaolin/Fly Ash Geopolymers with Chamotte Aggregate. Materials. 9(7), 535. DOI: 10.3390/ma9070535.

[7] N. Marjanović, M. Komljenović, Z. Baščarević, V. Nikolić. (2014). Improving reactivity of fly ash and properties of ensuing geopolymers through mechanical activation. Construction and Building Materials. 57, 151-162. DOI: 10.1016/j.conbuildmat.2014.01.095.

[8] B. V. Rangan. (2008). Fly ash-based geopolymer concrete. Research Report GC 4. Curtin University of Technology. Engineering Faculty. Perth, Australia. 
[9] A. Palomo, M. W. Grutzeck, M. T. Blanco. (1999). Alkali-activated fly ashes-Cement for the future. Cement and Concrete Research. 29, 1323-1329. DOI: 10.1016/S0008-8846(98)002439.

[10] A. Palomo, A. Fernández-Jiménez. (2011). Alkaline activation, procedure for transforming fly ash into new materials. In World of Coal Ash (WOCA) Conference. May 9-12, 1-14, Denver USA.

[11] D. Khale, R. Chaudhary. (2007). Mechanism of geopolymerization and factors influencing its development: a review. Journal of Materials Science. 42(3), 729-746. DOI: 10.1007/s10853006-0401-4.

[12] M. F. Ahmed, M. F. Nuruddin, N. Shafiq. (2011). Compressive Strength and Workability Characteristics of Low-Calcium Fly ash-based Self-Compacting Geopolymer Concrete. International Journal of Civil, Environmental, Structural, Construction and Architectural Engineering. 5(2), 64-70.

[13] M.P.C.M. Gunasekara, D.W. Law, S. Setunge. (2014). Effect of composition of fly ash on compressive strength of fly ash based geopolymer mortar. In 23rd Australasian Conference on the Mechanics of Structures and Materials, 9.-12. December, 113-118. Byron Bay, Australia: Southern Cross University.

[14] D. Cross, J. Stephens, J. Vollmer. (2005). Field Trials of 100\% Fly Ash Concrete. Concrete International. 27(09), 47-51.

[15] Portland Cement Association. (2007). M. Thomas. Optimizing the Use of Fly Ash in Concrete. USA.

[16] S.S. Jamkar, Y.M. Ghugal, S.V. Patankar. (2013). Effect of Fineness of Fly Ash on Flow and Compressive Strength of Geopolymer Concrete. The Indian Concrete Journal. 57-61.

[17] D. Cresswell. (2016). Quarry Fines \& Paper Sludge in Manufactured Aggregate. Case Study WRT 177 / WR0115. Smart Waste, UK.

[18] B. González-Corrochano et al. (2016). Valorization of washing aggregate sludge and sewage sludge for lightweight aggregates production. Construction and Building Materials. 116. 252262. DOI: 10.1016/j.conbuildmat.2016.04.095.

[19] M. Želinková. (2014). The analysis of particle size of fly ashes - the possibility of obtaining fine particles by grinding. In Proceedings of Seminar of PhD. Students. 72-80. Kosice - TU.

[20] S. Yazici, S. Arel. (2012). Effects of fly ash fineness on the mechanical properties of concrete. Sadhana. 37(3), 389-403. DOI: 10.1007/s12046-012-0083-3.

[21] F. Škvara, T. Jílek, L. Kopecký. (2005). Geopolymer materials based on fly ash. Ceramics Silicate. 49(3), 195-204.

[22] Slovak Office of Standards, Metrology and Testing, Bratislava. (2001). Methods of test for mortar for masonry. Part 10: Determination of dry bulk density of hardened mortar. STN EN 1015-10.

[23] Slovak Office of Standards, Metrology and Testing, Bratislava. (1989). Determination of moisture, water absorption and capillarity of concrete. STN 731316.

[24] Slovak Office of Standards, Metrology and Testing, Bratislava. (2001). Methods of test for mortar for masonry. Part 11: Determination of flexural and compressive strength of hardened mortar. STN EN 1015-11.

[25] H.W. Nugteren et al. (2009). High Strength Geopolymers from Fractionated and Pulverized Fly Ash. In World of Coal Ash Conference, May 4-7. Lexington, USA.

[26] M. Chollet, M. Horgnies. (2011). Analyses of the surfaces of concrete by Raman and FT-IR spectroscopies: comparative study of hardened samples after demoulding and after organic post-treatment. Surface and Interface Analysis 43, 714-725. DOI: 10.1002/sia.3548. 
[27] M.M.A.B. Abdullah, et al. (2012). Fly ash-based geopolymer lightweight concrete using foaming agent. Internationa Journal of Molecular Sciences 13, 7186-7198. DOI: 10.3390/ijms13067186.

[28] A. Fernandez-Jimenez, A. Palomo. (2005). Composition and microstructure of alkali activated fly ash binder: Effect of the activator. Cement and Concrete Research 35, 1984-1992. DOI: 10.1016/j.cemconres.2005.03.003.

[29] A. Fernandez-Jimenez, A. Palomo. (2005). Mid-infrared spectroscopic studies of alkali activated fly ash structure. Microporous Mesoporous Mater. 86, 207-214. DOI: 10.1016/j.micromeso.2005.05.057.

[30] M. Criado, A. Palomo, A. Fernandez-Jimenez. (2005). Alkali activation of fly ashes. Part I. Effect of curing conditions on the carbonation of the reaction products. Fuel. 84, 2048-2054. DOI: 10.1016/j.fuel.2005.03.030.

[31] M.Y.A. Mollah, W.Y.R. Schennach, D.L. Cocke. (2000). A Fourier transform infrared spectroscopic investigation of the early hydration of Portland cement and the influence of sodium lignosulfonate. Cement and Concrete Research 30, 267- 273. DOI: 10.1016/S00088846(99)00243-4.

[32] J. Bensted. (1976). Examination of the hydration of slag and pozzolanic cement by infrared spectroscopy. Cemento. 73, 209-214.

[33] X. Guo, H. Shi, W.A. Dick. (2010). Compressive strength and microstructural characteristic of class C fly ash geopolymer. Cement and Concrete Research 32, 142-147. DOI: 10.1016/j.cemconcomp.2009.11.003. 